\title{
Enhancing the Capacity of Policy-Makers to Develop Evidence-Informed Policy Brief on Infectious Diseases of Poverty in Nigeria
}

\author{
Chigozie Jesse Uneke ${ }^{1,2^{*}}$, Abel Ebeh Ezeoha ${ }^{2,3}$, Henry Uro-Chukwu ${ }^{2,4}$, Chinonyelum Thecla Ezeonu ${ }^{2,5}$, \\ Ogbonnaya Ogbu ${ }^{2,6}$, Friday Onwe ${ }^{2,7}$, Chima Edoga ${ }^{2,8}$
}

\begin{abstract}
Background: The lack of effective use of research evidence in policy-making is a major challenge in most low- and middle-income countries (LMICs). There is need to package research data into effective policy tools that will help policy-makers to make evidence-informed policy regarding infectious diseases of poverty (IDP). The objective of this study was to assess the usefulness of training workshops and mentoring to enhance the capacity of Nigerian health policy-makers to develop evidence-informed policy brief on the control of IDP.

Methods: A modified "before and after" intervention study design was used in which outcomes were measured on the target participants both before the intervention is implemented and after. A 4-point Likert scale according to the degree of adequacy; 1 = "grossly inadequate," 4 = "very adequate" was employed. The main parameter measured was participants' perceptions of their own knowledge/understanding. This study was conducted at subnational level and the participants were the career health policy-makers drawn from Ebonyi State in the South-Eastern Nigeria. A oneday evidence-to-policy workshop was organized to enhance the participants' capacity to develop evidence-informed policy brief on IDP in Ebonyi State. Topics covered included collaborative initiative; preparation and use of policy briefs; policy dialogue; ethics in health policy-making; and health policy and politics.

Results: The preworkshop mean of knowledge and capacity ranged from 2.49-3.03, while the postworkshop mean ranged from $3.42-3.78$ on 4 -point scale. The percentage increase in mean of knowledge and capacity at the end of the workshop ranged from $20.10 \%-45 \%$. Participants were divided into 3 IDP mentorship groups (malaria, schistosomiasis, lymphatic filariasis $[\mathrm{LF}]$ ) and were mentored to identify potential policy options/recommendations for control of the diseases for the policy briefs. These policy options were subjected to research evidence synthesis by each group to identify the options that have the support of research evidence (mostly systematic reviews) from PubMed, Cochrane database and Google Scholar. After the evidence synthesis, five policy options were selected out of 13 for malaria, 3 out of 10 for schistosomiasis and 5 out of 11 for LF.

Conclusion: The outcome suggests that an evidence-to-policy capacity enhancement workshop combined with a mentorship programme can improve policy-makers' capacity for evidence-informed policy-making (EIP).

Keywords: Capacity, Policy-makers, Policy Brief, Infectious Diseases of Poverty (IDP), Nigeria

Copyright: (C) 2015 by Kerman University of Medical Sciences

Citation: Uneke CJ, Ezeoha AE, Uro-Chukwu H, et al. Enhancing the capacity of policy-makers to develop evidenceinformed policy brief on infectious diseases of poverty in Nigeria. Int J Health Policy Manag. 2015;4(9):599-610. doi:10.15171/ijhpm.2015.100
\end{abstract}

\section{Article History:}

Received: 19 February 2015 Accepted: 16 May 2015 ePublished: 20 May 2015

\section{Key Messages}

Implications for policy makers

- Policy-makers need to have access to the right information on infectious diseases of poverty (IDP) at the right time to inform decisions that draw on the evidence of what works. There are numerous reports which have shown that the availability of timely, suitably packaged and policy relevant research evidence is important in supporting increased use of research evidence in the policy processes.

- Policy-makers' knowledge and capacity to develop evidence-informed policy materials such as policy briefs can be enhanced via evidence-topolicy training workshops and mentorship programme.

- Any capacity enhancement initiative designed to enable policy-makers to prepare and use policy briefs effectively and efficiently, should contain knowledge and skills building components that will improve the following: (i) Policy-makers' ability to clarify policy relevant problems; (ii) Policy-makers' ability to decide on - and describe - the options to address the problem; (iii) Policy-makers' ability to identify and address barriers to implementing policy options; and (iv) Policy-makers' ability to organise and run policy dialogues.

Implications for public

There is the need to package research data into effective policy tools and materials that will help policy-makers to make and implement evidenceinformed policy regarding infectious diseases of poverty (IDP) to improve public health. Policy brief is an effective evidence-packaging mechanism which can support evidence-informed policy-making (EIP) on IDP, hopefully improving the chances of successful policy implementation. Research has shown that policy briefs can make it easier for policy-makers and other stakeholders to determine how available evidence from research can be contextualized locally and accords with their own beliefs, values, interests, or political goals and strategies. 


\section{Background}

In recent years, increasing attention has been paid to the use of research in the formulation of health policy as a way of enhancing its effectiveness. ${ }^{1}$ The process of utilizing evidence from research to make health policy is known as evidence-informed policy-making (EIP). EIP is characterized by the systematic and transparent access to, and appraisal of, evidence as an input into policy-making. ${ }^{2}$ Bowen and Zwi, ${ }^{3}$ noted that evidence encompasses research, and may include opinion and views of individuals or groups, results of consultative processes and published reports and documents. However, evidence from scientific research has been consistently shown to be among the most reliable category of evidence in the development of health policy.4 ${ }^{4-7}$ Oxman and colleagues $^{2}$ in their report on SUPPORT tools for evidenceinformed health policy-making, cited several instances, such as the role of health services research in public policy-making; health policy-makers' perceptions of their use of evidence; and healthcare management and policy-making which showed that in the reality, health policies are often not well-informed by research evidence. ${ }^{7-10}$

Although there are promising experiences and a few documented success stories on how research evidence has been used to inform policy, ${ }^{11-13}$ the lack of effective use of research evidence in policy-making continues to be a major challenge in most low- and middle-income countries (LMICs) where health systems are weak and the burden of infectious diseases of poverty (IDP) is enormous. According to Oxman and colleagues, ${ }^{2}$ poorly-informed decision-making particularly in LMICs is one of the reasons why services sometimes fail to reach those most in need, why health indicators become off-track and why many affected countries are unlikely to be able to meet the health millennium development goals (MDGs). The World Health Organization (WHO) in the global report for research on IDP, ${ }^{14}$ noted that policy-makers need to have access to the right information at the right time to inform decisions that draw on the evidence of what works, and feed "best buys" into health policy, health budgets and the operations of health systems. The report further noted that research data must be rapidly translated into effective tools for policy-makers to enhance the control of IDP. ${ }^{14}$

In Nigeria, the need to package research data into effective policy tools and materials that will help policy-makers to make evidence-informed policy regarding IDP cannot be overstated. Malaria, schistosomiasis and lymphatic filariasis (LF) are among the IDP with severe health burden in Nigeria which require effective policy tools for their control. According to the World Malaria Report of 2014, it was estimated that in 2013, 128 million people were infected with Plasmodium falciparum malaria in Sub-Saharan Africa at any one time. ${ }^{15}$ In total, 18 countries accounted for $90 \%$ of infections in SubSaharan Africa; 37 million infections (29\%) arose in Nigeria and 14 million (11\%) in the Democratic Republic of the Congo, the 2 countries with the highest numbers of infections. ${ }^{15}$ With regards to LF, available recent reports indicate that in Africa, 34 countries are endemic, and Nigeria is believed to bear the highest burden of LF, with an estimated 80 to 120 million people at risk. ${ }^{16-18}$ In a recent review article, Adenowo and colleagues $^{19}$ noted that schistosomiasis is the second most common neglected tropical disease after hookworm in SubSaharan Africa and accounts for 93\% (192 million) of the world estimated 207 million cases of schistosomiasis with the highest prevalence of the infection seen in Nigeria (29 million).

Adam and colleagues ${ }^{20}$ observed that there is the growing recognition of the importance of developing concise materials and tools to communicate various types of information to policy-makers and those supporting them. They cited several reports where this recognition has led to the development of a plethora of information-packaging efforts, which aim to support action based on the messages arising from research and other policy-relevant information. ${ }^{21-23}$

There are numerous reports which have shown that the availability of timely, suitably packaged and policy relevant research evidence is important in supporting increased use of research evidence in the policy processes in LMICs. ${ }^{20-23} \mathrm{~A}$ number of studies have shown that effective techniques for communicating research findings to decision-makers include presenting readily understandable; timely data in visually compelling formats; using illustrative anecdotes where appropriate; sending clear key messages about the meaning of data; suggesting ways to use research findings for answering important policy questions; and establishing relationships of trust and credibility with policy-makers. ${ }^{24-27}$

In a report on preparing and using evidence-informed policy briefs to support EIP, Lavis and colleagues, ${ }^{28}$ noted that policy brief is an effective evidence-packaging mechanism and a new approach to improving the policy-making process by supporting evidence-informed policy-making. They noted that policy briefs make it easier for policy-makers and other stakeholders to determine whether and how the available research evidence accords with their own beliefs, values, interests, or political goals and strategies. ${ }^{28}$ An effective policy brief has been described as one that makes the evidence concise and understandable; explains why the evidence is important; and describes evidence-informed policy options that would be suitable actions for policy-makers to take. ${ }^{29-31}$ With a problem clarified in a policy brief, what is known and not known about the options clearly described, and key implementation considerations clearly flagged, policy-makers may be more readily able to identify viable ways forward. ${ }^{28}$ It is pertinent to state that despite the existence and importance of effective evidence-packaging mechanisms such as policy briefs in the promotion of EIP, most policymakers particularly in LMICs lack the capacity to develop and use them. In a WHO publication on enhancing capacity for evidence-informed health policy, it was observed that policymakers' capacity to understand and use research (including evidence-packaging mechanisms) has been neglected, both as a research topic and as an area of investment in terms of promoting evidence-informed policy. ${ }^{32}$

There are reports that have indicated a strong need for capacity-building, for policy-makers to enable them have a better understanding of scientific information packaged in various policy-relevant formats, along with civil servants in a number of ministries in national and local government. ${ }^{1,33,34}$ Oxman and colleagues ${ }^{2}$ have argued that strengthening the use of research evidence (including through policy briefs), and the ability of policy-makers to make appropriate judgments 
about its relevance and quality, is a critical challenge that holds the promise of helping to achieve significant health gains and better use of resources.

A variety of techniques to accomplish capacity enhancement for policy-makers include sharing of information through publications, training workshops, mentoring, hosting and facilitating networks and knowledge services, and participating in and supporting relevant research. ${ }^{1,35}$ The objective of this study was to assess the usefulness of training workshops and mentoring to enhance the capacity and ethical standards of Nigerian health policy-makers from the State of Ebonyi to develop policy briefs on the control of IDP.

\section{Methods}

Study Design

A modified "before and after" intervention study design was used in this investigation as described by Purdon and colleagues. ${ }^{36}$ The outcomes were measured on the eligible population (target participants) both before the intervention is implemented and after. The difference between the before and after measurements was taken to be the impact of the intervention. In this instance, the 'before'-or 'baseline' - measurements served as the control measurements. ${ }^{36}$ The study was divided into 2 stages: (i) Evidence to policy workshop; and (ii) Policy-makers' mentorship meetings. Detailed description of these stages is provided in the relevant sections below.

\section{Study Area and Participants}

This study was conducted at subnational level and the participants were drawn from Ebonyi State in the SouthEastern Nigeria. The target participants were the career health policy-makers, as described by Bammer and colleagues ${ }^{37}$ and these include health professionals in charge of the health system's management; regional, state and local government directors of Ebonyi State health ministry; directors of primary healthcare at the local government level; health professionals working with specific programmes in the health ministry; staff and consultants involved in public health issues within the health ministry; programme/project managers under the health ministry; chief executive officers of civil society groups, including nongovernmental organizations (NGOs); and leaders of national health-based associations (for example, Nigeria Medical Association; National Association of Nigeria Nurses and Midwives; and Pharmaceutical Association of Nigeria).

\section{Evidence-to-Policy Workshop}

A total of 50 policy-makers were mapped out for this study. We organized a one-day evidence-to-policy workshop at the Ebonyi State Civil Service Staff Development Centre Abakaliki Nigeria, for the policy-makers. The focus of the evidence-to-policy workshop was to enhance the participants' capacity to develop evidence-informed policy briefs on IDP in Ebonyi State. The topics and content of the evidence-topolicy workshop are outlined in Table 1. All the policymakers were invited to the workshop by invitation letters which were sent 2 weeks before the event and was followedup with a text message reminder to their mobile phones a day before the programme. Of the 50 invited policy-makers 43 individuals attended. The workshop was held in October 2014. The duration of the workshop was 7 hours from 9 AM to 4 PM (with a break between 12 Noon to $1 \mathrm{PM}$ ).

A preworkshop assessment questionnaire (developed in a 4-point Likert scale according to the degree of adequacy; $1=$ grossly inadequate, 4 = very adequate), was administered prior to actual training to assess the level of knowledge and capacity of the participants on the specific topics to be covered within the theme of the workshop. After the administration of the preworkshop questionnaire the training commenced and was facilitated by 4 resource persons (3 senior researchers from Ebonyi State University and 1 senior director from the health ministry). All teaching sessions lasted 35-45 minutes and were done using PowerPoint presentation and handouts on each topic were produced and distributed to all participants. Questions/answers/discussions lasting from 30-40 minutes followed each teaching session. It was made mandatory for all lectures to be delivered in simplified, practical and easily comprehensible patterns. All teachings and discussions irrespective of the topical area focused on IDP. Emphasis was placed on development of policy on the control of malaria, schistosomiasis and LF in Ebonyi State. At the end

Table 1. Topics and Content of the Evidence-to-Policy Workshop for Policy-Makers in Ebonyi State Nigeria

\begin{tabular}{|c|c|}
\hline Topical Area & Contents \\
\hline $\begin{array}{l}\text { Collaborative initiative and the } \\
\text { benefits in health policy-making } \\
\text { for control of IDP }\end{array}$ & $\begin{array}{l}\text { The principles and framework of collaborative initiative; setting vision for collaboration; setting out the guiding } \\
\text { principles for collaboration; defining and setting goals and objectives of collaborative initiative; roles and responsibilities } \\
\text { of collaborative initiative; implementation requirements in collaborative initiative; and the evaluation process of } \\
\text { collaborative initiative }\end{array}$ \\
\hline $\begin{array}{l}\text { Preparation and use of policy } \\
\text { briefs in health policy-making } \\
\text { for control of IDP }\end{array}$ & $\begin{array}{l}\text { Agenda/priority setting; policy briefs in health policy-making; process of preparation of policy briefs; the key ingredients } \\
\text { of effective policy briefs; structure/outline of a policy brief ; value of policy briefs in health policy development }\end{array}$ \\
\hline $\begin{array}{l}\text { Policy dialogue in health policy- } \\
\text { making for control of IDP }\end{array}$ & $\begin{array}{l}\text { Policy dialogues in health policy-making; the importance of policy dialogue in the health systems and public health reform; } \\
\text { policy dialogue as an interactive knowledge-sharing mechanism; procedure for organising and using policy dialogues to } \\
\text { support EIP; characteristics and features of policy dialogues; the differences between dialogue and debate }\end{array}$ \\
\hline $\begin{array}{l}\text { Ethics in health policy-making, } \\
\text { research and implementation } \\
\text { for control of IDP }\end{array}$ & $\begin{array}{l}\text { Ethics in health policy research and implementation; the basic principles of ethics that must be implemented; balancing } \\
\text { ethical concerns with economic realities; impact of various policies on the vulnerable population; the principles of justice, } \\
\text { equity and autonomy; the ethical issues in health systems research }\end{array}$ \\
\hline
\end{tabular}
to manage political interference in the health policy-making process and implementation

Abbreviations: IDP, infectious diseases of poverty; EIP, evidence-informed policy-making. 
of the workshop, a postworkshop assessment questionnaire (also developed in a Likert scale format) was administered to the participants to evaluate the impact of the workshop. In preparation for the policy-makers' mentorship meetings (described below), at the end of the evidence-to-policy workshop participants were classified into 3 mentorship groups (malaria policy brief group; schistosomiasis policy brief group; and LF policy brief group). The classification was done according to participants' area of interest and work. Each policy group had 10-15 policy-makers as members and had 2 mentors assigned to each group. The mandate of each group was to develop a policy brief.

\section{Policy-makers' Mentorship Meetings}

The mentorship meetings took place from November to December 2014. The purpose of the policy-makers' mentorship meetings was to provide technical guidance to each of the policy-makers' policy group to enable them produce the respective policy briefs. A "formal group mentorship" approach described by the Canadian Coalition for Global Health Research ${ }^{38}$ was adopted in this study. The knowledge acquired during the evidence-to-policy workshop was put into use in the mentorship meetings. A total of four senior researchers from Ebonyi State University and one senior director from the health ministry served as mentors and provided technical guidance to the policy-makers' groups. The meetings were practical oriented and provided for full participation of every group member. Within the period of the mentorship, 2 major group meetings were held by each group (lasting 2-3 hours); these were in addition to the several individual meetings/contacts with the mentors by members of the respective groups. During the first major group meeting of each group, participants identified potential policy options/recommendations for the control of their respective IDP of focus. The policy options were based on their personal professional experiences, tacit knowledge, expert opinion and to some extent known research evidence. These policy options were subjected to "research evidence synthesis" (implies synthesising evidence largely from systematic reviews) by the each group to identify the options that have the support of research evidence. Research evidence (mostly systematic review) was sought from PubMed, Cochrane database and Google Scholar. During the second major group meeting, the policy options with sufficient research evidence were identified, deliberated upon and adopted for the policy brief drafting. Two members of each group were selected by the various groups to make a policy presentation of each group's resolution at a scheduled multi-stakeholders policy dialogue.

\section{Data Analysis}

The data collected via the questionnaire was analyzed using the methods developed at McMaster University Canada by Johnson and Lavis. ${ }^{39}$ The analysis is based on mean rating (MNR), median rating (MDR) and range. For instance the figures represent Likert rating scale of 1-4 points, where 1 point=grossly inadequate; 2 points=inadequate; 3 points =fairly adequate; and 4 points=very adequate. The main parameter measured was participants' perceptions of their own knowledge/understanding. In terms of analysis, values ranging from $1.00-2.49$ points are considered low, whereas values ranging from $2.50-4.00$ points considered high. The preworkshop means were compared to the postworkshop means. The EPi Info software was used for the performance of the data analysis.

Result

A total of 43 policy-makers out of the 50 individuals invited attended the workshop. The profile of the participants is presented in Table 2 and included the following: programme officer/project secretaries (31.58\%); managers/heads of departments (42.11\%); directors/presidents/chairpersons (26.32\%). A total of $55.26 \%$ of the participants have direct influence on the policy-making process, with $65.79 \%$ and $21.05 \%$ possessing bachelors and masters degrees as highest academic qualifications, respectively. The outcome of the assessment of the impact of the workshop with the comparison of the preworkshop means and postworkshop means is presented in Table 3. Result also showed progressive increase in the postworkshop mean over the preworkshop mean.

In terms of the "collaborative initiative," the preworkshop mean

Table 2. Profiles of the Participants During the Evidence-Based PolicyMaking Capacity Enhancement Workshop in Ebonyi State Nigeria

\begin{tabular}{|c|c|}
\hline Participant (Respondents) Attributes & $\begin{array}{l}\text { No. (\%) of Participants } \\
\text { (Respondents), } \mathrm{N}=38\end{array}$ \\
\hline \multicolumn{2}{|l|}{ Gender } \\
\hline Female & $22(57.89)$ \\
\hline Male & $16(42.11)$ \\
\hline \multicolumn{2}{|l|}{ Age (y) } \\
\hline $25-34$ & $5(13.16)$ \\
\hline $35-44$ & $11(28.95)$ \\
\hline$\geq 45$ & $22(57.89)$ \\
\hline \multicolumn{2}{|l|}{ Institutional affiliation } \\
\hline Federal Teaching hospital & $12(31.58)$ \\
\hline State Ministry of Health & $7(18.42)$ \\
\hline Local Government Service Commission & $14(36.84)$ \\
\hline NGO & $3(7.89)$ \\
\hline Educational institution & $1(2.63)$ \\
\hline (Missing) & $1(2.63)$ \\
\hline \multicolumn{2}{|l|}{ Official designation } \\
\hline Programme officer/project secretaries & $12(31.58)$ \\
\hline Managers/heads of departments & $16(42.11)$ \\
\hline Directors/presidents/chairpersons & $10(26.32)$ \\
\hline \multicolumn{2}{|l|}{ Years of experience in current designation } \\
\hline$<3$ & $11(28.95)$ \\
\hline $3-5$ & $10(26.32)$ \\
\hline $6-10$ & $14(36.84)$ \\
\hline$>10$ & $3(7.89)$ \\
\hline \multicolumn{2}{|l|}{ Influence on policy-making } \\
\hline Direct (DIPP) & $21(55.26)$ \\
\hline Indirect (IIPP) & $15(39.47)$ \\
\hline (Missing) & $2(5.26)$ \\
\hline \multicolumn{2}{|l|}{ Highest academic qualification } \\
\hline SSCE/diploma & $2(5.26)$ \\
\hline Bachelor & 25 (65.79) \\
\hline Masters & $8(21.05)$ \\
\hline Doctorate & $2(5.26)$ \\
\hline (Missing) & $1(2.63)$ \\
\hline
\end{tabular}

DIPP, direct influence on policy-making process; IIPP, indirect influence on policy-making process; SSCE, senior school certificate; NGO, nongovernmental organizations. 
Table 3. Comparison of the Preworkshop and Postworkshop Knowledge/Skill Assessment of Participants at the Evidence-to-Policy Training Workshop for the Research Capacity Strengthening and Knowledge Management for Policy-Makers in Ebonyi State Nigeria

\begin{tabular}{|c|c|c|c|}
\hline Parameter Assessed & $\begin{array}{l}\text { Preworkshop } \\
\text { Mean }\end{array}$ & $\begin{array}{l}\text { Postworkshop } \\
\text { Mean }\end{array}$ & $\begin{array}{c}\text { Mean } \\
\text { Increase (\%) }\end{array}$ \\
\hline \multicolumn{4}{|l|}{ Collaborative Initiative } \\
\hline $\begin{array}{l}\text { (i) How would you rate your understanding of the principles and framework of collaborative initiative in health } \\
\text { policy-making? }\end{array}$ & 3.03 & 3.68 & $0.65(21.45)$ \\
\hline $\begin{array}{l}\text { (ii) How would you describe your knowledge of setting vision for collaboration and the benefits in health policy- } \\
\text { making? }\end{array}$ & 2.97 & 3.63 & $0.66(22.22)$ \\
\hline $\begin{array}{l}\text { (iii) How would you describe your knowledge of setting out the guiding principles for collaboration and the } \\
\text { benefits in health policy-making? }\end{array}$ & 2.89 & 3.63 & $0.74(25.61)$ \\
\hline $\begin{array}{l}\text { (iv) How would you rate your understanding of defining and setting goals and objectives of collaborative } \\
\text { initiative in health policy-making? }\end{array}$ & 2.92 & 3.74 & $0.82(28.08)$ \\
\hline $\begin{array}{l}\text { (v) How would you describe your ability to understand and define roles and responsibilities of collaborative } \\
\text { initiative in health policy-making? }\end{array}$ & 3.00 & 3.63 & $0.63(21.00)$ \\
\hline $\begin{array}{l}\text { (vi) How would you rate your understanding of implementation requirements in collaborative initiative in health } \\
\text { policy-making? }\end{array}$ & 2.69 & 3.47 & $0.78(29.00)$ \\
\hline $\begin{array}{l}\text { (vii) How would you rate your understanding of the evaluation process of collaborative initiative in health policy- } \\
\text { making? }\end{array}$ & 2.68 & 3.61 & $0.93(34.70)$ \\
\hline \multicolumn{4}{|l|}{$\begin{array}{ll} & \text { Policy Briefs } \\
\end{array}$} \\
\hline $\begin{array}{l}\text { (i) How would you describe your level of knowledge of agenda/priority setting in the development of health } \\
\text { policy? }\end{array}$ & 2.89 & 3.73 & $0.84(29.07)$ \\
\hline (ii) How would you rate your understanding of policy briefs in health policy-making? & 2.79 & 3.61 & $0.82(29.39)$ \\
\hline $\begin{array}{l}\text { (iii) How would you describe your level of knowledge of the process of preparation of policy briefs in the } \\
\text { development of health policy? }\end{array}$ & 2.58 & 3.63 & $1.05(40.70)$ \\
\hline $\begin{array}{l}\text { (iv) How would you describe your level of knowledge of the key ingredients of effective policy briefs in the } \\
\text { development of health policy? }\end{array}$ & 2.49 & 3.61 & $1.12(45.98)$ \\
\hline $\begin{array}{l}\text { (v) How would you describe your level of knowledge of the structure/outline of a policy brief in the development } \\
\text { of health policy? }\end{array}$ & 2.54 & 3.47 & $0.93(36.61)$ \\
\hline $\begin{array}{l}\text { (vi) How would you describe your level of knowledge of the value of policy briefs in the development of health } \\
\text { policy? }\end{array}$ & 2.82 & 3.66 & $0.84(29.79)$ \\
\hline \multicolumn{4}{|l|}{ Policy Dialogue } \\
\hline (i) How would you rate your understanding of policy dialogues in health policy-making? & 2.79 & 3.63 & $0.84(30.11)$ \\
\hline $\begin{array}{l}\text { (ii) How would you rate your knowledge of the importance of policy dialogue in the health systems and public } \\
\text { in health reform? }\end{array}$ & 3.00 & 3.61 & $0.61(20.33)$ \\
\hline $\begin{array}{l}\text { (iii) How would you describe your understanding of the developments that necessitate hosting a policy dialogue } \\
\text { as an interactive knowledge-sharing mechanism? }\end{array}$ & 2.68 & 3.50 & $0.82(30.60)$ \\
\hline $\begin{array}{l}\text { (iv) How would you rate your knowledge of the procedure for organising and using policy dialogues to support } \\
\text { EIP? }\end{array}$ & 2.76 & 3.50 & $0.74(26.81)$ \\
\hline $\begin{array}{l}\text { (v) How would you rate your understanding of the characteristics and features of policy dialogues in health } \\
\text { policy-making? }\end{array}$ & 2.70 & 3.42 & $0.72(26.67)$ \\
\hline $\begin{array}{l}\text { (vi) How would you describe your understanding of the differences between dialogue and debate with respect } \\
\text { to the health policy-making process? }\end{array}$ & 2.89 & 3.59 & $0.70(24.22)$ \\
\hline \multicolumn{4}{|l|}{ Ethics in Health Policy Research and Implementation } \\
\hline (i) How would you rate your understanding of ethics in health policy research and implementation? & 2.76 & 3.74 & $0.98(35.51)$ \\
\hline $\begin{array}{l}\text { (ii) How would you rate your knowledge of the basic principles of ethics that must be implemented in virtually } \\
\text { any context in health policy-making? }\end{array}$ & 2.71 & 3.76 & $1.05(38.75)$ \\
\hline $\begin{array}{l}\text { (iii) How would you describe your understanding of balancing Ethical concerns with economic realities with } \\
\text { respect to the health policy-making process? }\end{array}$ & 2.53 & 3.66 & $1.13(44.66)$ \\
\hline $\begin{array}{l}\text { (iv) How would you describe your understanding of impact of various policies on the vulnerable population with } \\
\text { respect to the health policy-making process? }\end{array}$ & 2.61 & 3.70 & $1.09(41.76)$ \\
\hline $\begin{array}{l}\text { (v) How would you rate your knowledge of the principles of Justice, equity and autonomy in health policy-making } \\
\text { process? }\end{array}$ & 2.76 & 3.73 & $0.97(35.14)$ \\
\hline (vi) How would you rate your knowledge of the ethical issues in health service research? & 2.79 & 3.78 & $0.99(35.48)$ \\
\hline \multicolumn{4}{|l|}{$\begin{array}{ll}\text { Health Policy and Politics in Ebonyi State } \\
\end{array}$} \\
\hline (i) How would you rate your understanding of the principles of health policy and politics in Ebonyi State? & 2.89 & 3.47 & $0.58(20.07)$ \\
\hline $\begin{array}{l}\text { (ii) How would you rate your knowledge of how local politics can affect health policy formulation and } \\
\text { implementation? }\end{array}$ & 3.03 & 3.59 & $0.56(18.48)$ \\
\hline $\begin{array}{l}\text { (iii) How would you describe your understanding of how to manage political interference in the health policy- } \\
\text { making process and implementation? }\end{array}$ & 2.87 & 3.62 & $0.75(26.13)$ \\
\hline
\end{tabular}

Abbreviations: IDP, infectious diseases of poverty; EIP, evidence-informed policy-making. 
ranged from 2.69-3.03, while the postworkshop mean ranged from 3.47-3.74, with the percentage increase ranging from $21.00 \%-34.70 \%$. In terms of "preparation and use of policy briefs," the preworkshop mean ranged from 2.49-2.89, while the postworkshop mean ranged from $3.47-3.73$, with the percentage increase ranging from $29.07 \%-44.98 \%$. In terms of "policy dialogue," the preworkshop mean ranged from 2.683.00 , while the postworkshop mean ranged from 3.42-3.63, with the percentage increase ranging from $20.33 \%-30.60 \%$. Concerning "ethics in health policy-making" the preworkshop mean ranged from 2.53-2.79, while the postworkshop mean ranged from 3.66-3.78, with the percentage increase ranging from $35.14 \%-44.66 \%$. With regard to "health policy and politics," the preworkshop mean ranged from 2.87-3.03, while the postworkshop mean ranged from $3.47-3.62$, with the percentage increase ranging from $18.48 \%-26.13 \%$ (Table 4 ). The outcome of the group mentorship meetings is presented in Tables 5, 6 and 7. Of the 13 policy options recommended by the malaria policy brief group, 5 options were eventually accepted after the "evidence synthesis" (ie, synthesising evidence largely from systematic reviews)..$^{40-47}$ These included the following: (i) Distribution of insecticide treated bednets (ITNs) to be more effective, proper orientation on the usage; (ii) Laboratory diagnosis of malaria to be considered along clinical assessment before treatment of malaria; (iii) artemisinin combination therapies (ACTs) recommended but quality control must be ensured; (iv) More funding for research on indigenous malaria drugs; and $(v)$ Vector control using indoor residual spraying and larval source management. The option on restriction of antimalarial prescription as an over the counter (OTC) drug, was replaced with option that chemists to perform rapid diagnostic test for malaria (RDT) before giving antimalarials (Table 5 ). Of the 10 policy options recommended by the schistosomiasis policy brief group, only 3 were accepted after the evidence synthesis. ${ }^{48-50}$ These included the following: ( $i$ ) Control of snail vectors; ( $i$ i) Periodic enlightenment of the community/health education/part of school training curriculum on communicable diseases; and (iii) Mass screening/chemotherapy. The rest were rejected due to lack of sufficient research evidence supporting their use for policy (Table 6). Of the 11 policy options recommended by the LF policy brief group, only 5 were accepted after the evidence synthesis. ${ }^{51-56}$ These included the following: (i) Establishment of a standard protocol for diagnosis for LF; (ii) Vector control; (iii) Community directed distribution of long lasting insecticide treated bed-net (LLN) and Mectizan (Mass chemotherapy)/health education; (iv) Integrated control policy (onchocerciasis, schistosomiasis, and LF); and $(v)$ Establishment of policy monitoring/evaluation (feedback mechanism)/with training and capacity building. The remaining options were rejected because of absence of sufficient evidence (Table 7).

\section{Discussion}

The outcome of this study suggests that policy-makers' knowledge and capacity to develop evidence-informed

Table 4. Participants Written Comments at the End of the Evidence-to-Policy Workshop for Policy-Makers in Ebonyi State

1. The workshop is an eye opener to the context of influencing policy direction at our levels ensuring best practices and encouraging team/collaborative approach.

2. The workshop is been very interesting but there is no time to digest the papers well. We need more of this programme.

3. The lectures were well-packaged and educating

4. I appreciate the organiser for their elaboration and in-depth knowledge about EIP.

5. My observation is that this course should be extended to more days not only one day.

6. This training is very good for policy influencers like us.

7. Political stakeholders should be involved in this project because this will enable them realize their role and collaborate with us.

8. This training is very educating and brain storming and must be continued.

9. I am better informed now about the global best practices of health policy-making.

10. The papers presented were all master piece in my every day activities.

11. Interesting and eye opener in policy-making decision process.

12. Workshop of this kind should be organised regularly for us to be masters in the process.

13. Bureaucracy and administrative bottleneck often impede us from acting and going what we are supposed to do what will you do about these things?

14. This health policy programme should be organised least every 3 months for us to be well-equipped in the rudiments policy-making.

15. This programme should be sustained by organising it every month.

16. This is very beneficial to policy-makers and influencers.

17. More political advocacy in order to help us break through with its implementations.

18. Some knowledge are not very adequate.

19. This has increased my knowledge on policy brief especially its collaborative nature.

20. This is very vital for us the policy-makers and periodic interaction like this should be encouraged and sustained.

21. This workshop is what we need to be part of.

22. The presentations are very friendly and understandable we pray for the presenters for more wisdom.

23. There must be more practical approach this than academics because the rivals between politics and needs will not give us a favourable ground to implement this evidenced-based policy-making process.

Abbreviation: EIP, evidence-informed policy-making. 
Table 5. Malaria Control Policy Recommendations and Outcome of Evidence Synthesis by the Malaria Policy Brief Group

\begin{tabular}{|c|c|c|}
\hline $\begin{array}{l}\text { Policy Options Recommended Before } \\
\text { Evidence Synthesis }\end{array}$ & Outcome of Evidence Synthesis of Policy Options Recommended & $\begin{array}{l}\text { Group Conclusion and Final } \\
\text { Recommendation }\end{array}$ \\
\hline $\begin{array}{l}\text { (1) Environmental manipulation, } \\
\text { modification, and management (provision } \\
\text { of good drainage system) }\end{array}$ & $\begin{array}{l}\text { No available evidence as a feasible strategy for malaria control policy. } \\
\text { Alternative: Larval source management under vector control feasible. } \\
\text { Key Reference: Tusting et al }{ }^{40}\end{array}$ & $\begin{array}{l}\text { Policy option rejected. } \\
\text { Alternative accepted as policy } \\
\text { recommendation. }\end{array}$ \\
\hline (2) Proper refuse disposal & No available evidence as a feasible strategy for malaria control policy. & Policy option rejected. \\
\hline $\begin{array}{l}\text { (3) Sanctions for environmental sanitation } \\
\text { violators }\end{array}$ & No available evidence as a feasible strategy for malaria control policy. & Policy option rejected. \\
\hline $\begin{array}{l}\text { (4) Private sector involvement in } \\
\text { management of waste disposal }\end{array}$ & No available evidence as a feasible strategy for malaria control policy. & Policy option rejected. \\
\hline $\begin{array}{l}\text { (5) Distribution of ITNs to be more } \\
\text { effective, proper orientation on the usage }\end{array}$ & $\begin{array}{l}\text { There is sufficient evidence to show it is an effective strategy for malaria } \\
\text { control policy. Key reference: Gamble et } \mathrm{al}^{41}\end{array}$ & Policy option accepted. \\
\hline $\begin{array}{l}\text { (6) Use of drugs to eradicate the parasite } \\
\text { in the population (mass chemotherapy } \\
\text { with gametocidal agent) }\end{array}$ & $\begin{array}{l}\text { There is evidence to show that it is an effective strategy for malaria control. } \\
\text { However there are serious implementation challenges especially with the } \\
\text { sustainability of this strategy. Its feasibility as a policy recommendation for } \\
\text { Ebonyi is doubtful. Key reference: Poirot et al }{ }^{42}\end{array}$ & Policy option rejected. \\
\hline (7) Provision of portable water & No available evidence as a feasible strategy for malaria control policy. & Policy option rejected. \\
\hline $\begin{array}{l}\text { ( } 8 \text { ) Laboratory diagnosis of malaria to } \\
\text { be considered along clinical assessment } \\
\text { before treatment of malaria should be } \\
\text { considered }\end{array}$ & $\begin{array}{l}\text { There is sufficient evidence to show it is an effective strategy for malaria } \\
\text { control policy. Key reference: Odaga et } \mathrm{al}^{43}\end{array}$ & Policy option accepted. \\
\hline $\begin{array}{l}\text { (9) Restriction of antimalarial prescription } \\
\text { as an OTC drug to prevent resistance } \\
\text { (strengthen PHCC in rural areas) }\end{array}$ & $\begin{array}{l}\text { There is insufficient evidence to show that it can be an effective strategy } \\
\text { for malaria control. There can be serious implementation challenges } \\
\text { especially with the sustainability of this strategy. Its feasibility as a policy } \\
\text { recommendation for Ebonyi is doubtful, except if the PHCC is greatly } \\
\text { strengthened. Alternative: Chemists to perform RDT before giving } \\
\text { antimalarials. Key reference: Abuya et al }{ }^{44}\end{array}$ & $\begin{array}{l}\text { Policy option rejected. } \\
\text { Alternative accepted as policy } \\
\text { recommendation. }\end{array}$ \\
\hline $\begin{array}{l}\text { (10) ACTS recommended but quality } \\
\text { control must be ensured }\end{array}$ & $\begin{array}{l}\text { There is sufficient evidence to show it is an effective strategy for malaria } \\
\text { control policy. Key reference: Ogbonna and Uneke }{ }^{45}\end{array}$ & Policy option accepted. \\
\hline $\begin{array}{l}\text { (11) Improvement of incentives to the } \\
\text { rural health workers }\end{array}$ & $\begin{array}{l}\text { No available evidence as a feasible strategy for malaria control. Beyond the } \\
\text { scope of malaria policy alone. This is a health sector general problem. }\end{array}$ & Policy option rejected. \\
\hline $\begin{array}{l}\text { (12) More funding for research on } \\
\text { indigenous malaria drugs }\end{array}$ & $\begin{array}{l}\text { There is sufficient evidence to show it is an effective strategy for malaria } \\
\text { control policy. Key reference: Amoa Onguéné et } \mathrm{al}^{46}\end{array}$ & Policy option accepted. \\
\hline $\begin{array}{l}\text { (13) Vector control using indoor residual } \\
\text { spraying and larval source management }\end{array}$ & $\begin{array}{l}\text { There is sufficient evidence to show it is an effective strategy for malaria } \\
\text { control policy. Key references: Tusting et al }{ }^{40} \text {; Pluess et } a l^{47}\end{array}$ & Policy option accepted. \\
\hline
\end{tabular}

Abbreviations: OTC, over the counter; ITN, insecticide treated bed-net; PHCC, primary health care centre; RDT, rapid diagnostic test for malaria; ACT, artemisinin combination therapy.

policy materials such as policy briefs can be enhanced via a one day training workshop followed by a mentorship program. The Ebonyi State University provided the enabling platform for the study team to execute this training and mentorship venture designed to promote evidence-to-policy link. According to WHO, the education sector, especially universities, has a role to play in building capacity and fostering interdisciplinary learning in a new generation of scientists and policy-makers. ${ }^{14}$ We adopted training workshop in this evidence-to-policy capacity enhancement initiative because of its many strategic benefits. The report of healthcare information for all (HIFA $)^{57}$ highlighted some of the benefits of training workshop (when used as in-service training) to include presenting new information to groups of people, practicing new skills and allowing health workers to share experiences and insights. The methods we adopted in the workshops include the use of preworkshop questionnaire and postworkshop questionnaire; general discussions; group works and short presentations have been shown to be very effective in capacity enhancement of decision makers. ${ }^{58}$ The comments from selected participants concerning the outcome of the workshop, clearly showed that notable improvement in knowledge and capacity was achieved (Table 3). One policymaker stated thus: "I am better informed now about the global best practices of health policy-making"; another noted that: "The workshop is an eye opener to the context of influencing policy direction at our levels ensuring best practices and encouraging team and collaborative approach."

Unlike training workshops, mentoring is rarely applied in the enhancement of policy-makers' capacity for knowledge management as well as evidence-based policy-making. In a previous report, Bennett et $\mathrm{a}^{59}$ noted that mentoring has emerged as a critical strategy and key to enhance capacity for evidence-based policy-making and health systems research. In this study the success in the process of guiding the policymakers to be able to identify policy options and subject the options to evidence synthesis suggest that mentorship can be a vital tool in policy-makers' capacity enhancement. The Canadian Coalition for Global Health Research (CCGHR) report ${ }^{38}$ described mentorship as a resource for building sustainable capacity, fostering research capacity and nurturing leadership development in the context of limited resources. Furthermore the report noted that a very vital aspect of mentorship is that it plays a critical role in this 
Table 6. Schistosomiasis Control Policy Recommendations and Outcome of Evidence Synthesis by the Schistosomiasis Policy Brief Group

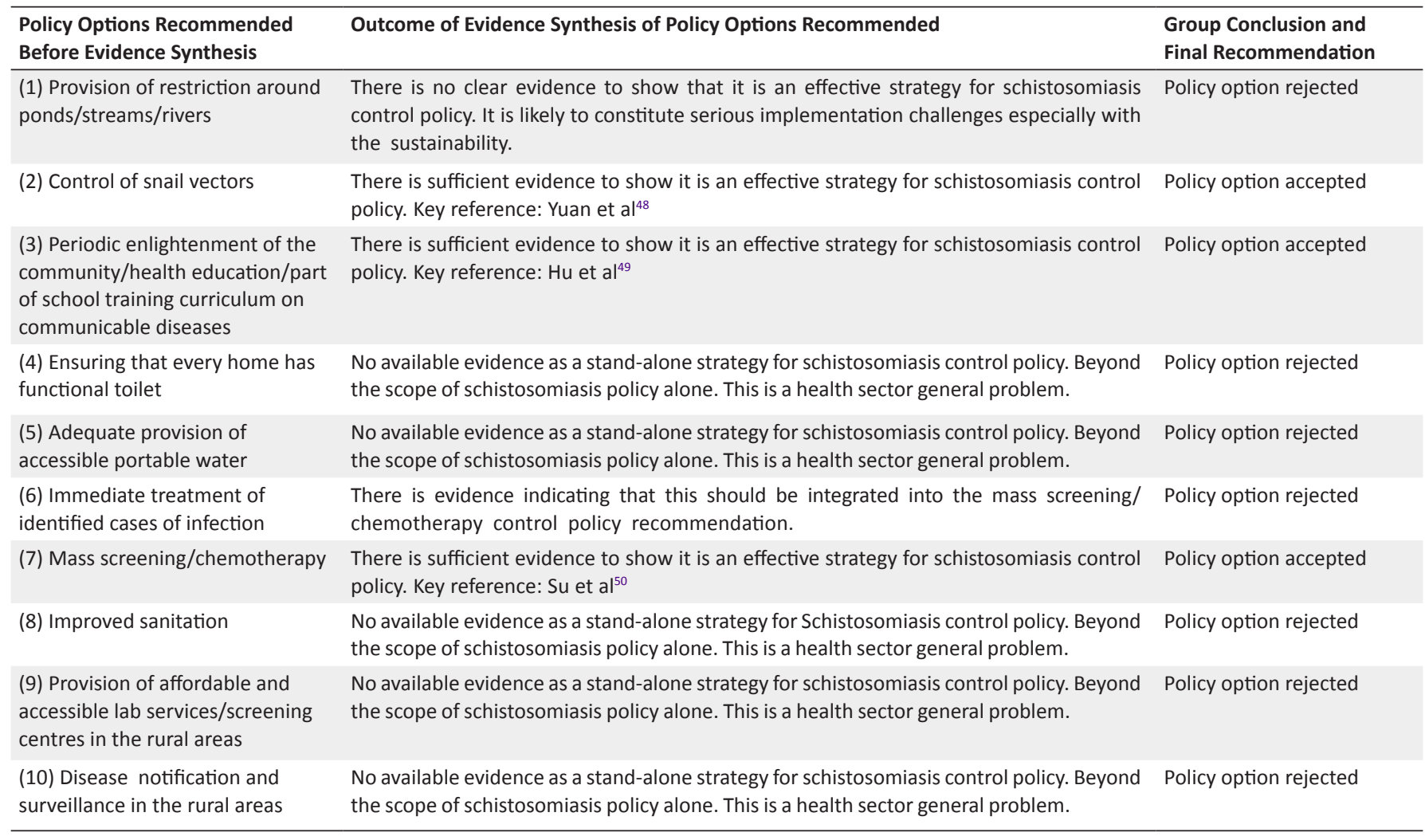

cycle of sustainable capacity building by developing the skills, knowledge, experiences and capacities through creating environments of continuous learning and sharing. ${ }^{38}$

The result of this study showed a notable improvement in the knowledge and capacity of the participants regarding the process of developing evidence-informed policy brief. This notable improvement is demonstrated by the tremendous increase in the postworkshop mean of knowledge/skill over that of the preworkshop mean in all the subject areas covered at the evidence-to-policy workshop. It is worth noting that among the areas of greatest knowledge and capacity improvement was in the development of evidence-informed policy brief. The percentage increase in knowledge ranged from $36.61 \%$ to $45.00 \%$ for knowledge of the process of preparation of policy briefs; knowledge of the key ingredients of effective policy briefs; and knowledge of the structure/ outline of a policy brief. This perhaps suggests that it may be the area of the policy-makers' greatest capacity constraint in EIP process. Deans and Ademokun ${ }^{1}$ had argued that those who seek to build capacity for evidence-informed policy need to understand the actual capacity gaps of policy-makers. Nonetheless, preparing and using policy briefs by policymakers requires a range of knowledge and skills, including the ability to clarify problems, to decide on-and describe - the options to address the problem, to identify and address barriers to implementing the options, and to organise and run policy dialogues. ${ }^{35}$ Securing this capacity among policymakers will help to ensure that policy briefs are produced and used more effectively and efficiently. ${ }^{35}$

Apart from enhancing policy-makers' ability to develop policy briefs, we incorporated other vital policy relevant subjects including collaborative initiative; health policy and politics; and ethics in policy-making/implementation. According to Green and Bennett, ${ }^{32}$ policy-making does not take place in a vacuum: political, economic and social factors all affect how policies are made, and who makes them, at all levels. We introduced collaborative initiative to demonstrate to the policy-makers that policy-making is a multidisciplinary venture requiring the partnership with all relevant stakeholders. This is because partnerships provide a means of bridging complementary disciplines and provide opportunities for capacity strengthening through ideas and skills. ${ }^{32}$ The importance of politics in the health policy-making process cannot be ignored. Green and Bennett ${ }^{32}$ noted that policy process is political and often involves contestation between actors whose beliefs, values, knowledge and interests do not necessarily coincide. This explains why Prewitt ${ }^{60}$ argued for a change in metaphor from evidence-based policy to evidence-influenced politics, which acknowledges the central role played by political factors. According to Overseas Development Institute (ODI), ${ }^{61}$ the policy process and the production of research are in themselves political processes from start to finish.

This is why we integrated the political process in this study as a vital capacity enhancement area for the policy-makers. Our take on this is that if the policy-makers have a better understanding about the relationship between policy-making and politics they will be able to make effective policy. We also gave consideration to the subject of ethics in policymaking and enhanced the knowledge of the participants on how to apply it in policy-making. According to Aarons, ${ }^{62}$ the development of policies in health and healthcare should incorporate ethical premises as well as thoughtful consideration of the values pertinent to the particular society 
Table 7. LF Control Policy Recommendations and Outcome of Evidence Synthesis by the LF Policy Brief Group

\begin{tabular}{|c|c|c|}
\hline $\begin{array}{l}\text { Policy Options Recommended Before } \\
\text { Evidence Synthesis }\end{array}$ & Outcome of Evidence Synthesis of Policy Options Recommended & $\begin{array}{l}\text { Group Conclusion and } \\
\text { Final Recommendation }\end{array}$ \\
\hline $\begin{array}{l}\text { (1) Establishment of a standard protocol } \\
\text { for diagnosis of LF }\end{array}$ & $\begin{array}{l}\text { There is sufficient evidence to show it is an effective strategy for LF control policy. } \\
\text { Key reference: Weil et al }{ }^{51}\end{array}$ & Policy option accepted \\
\hline (2) Establishment of game reserve & No available evidence as a feasible strategy for LF control. & Policy option rejected \\
\hline (3) Vector control & $\begin{array}{l}\text { There is sufficient evidence to show it is an effective strategy for LF control policy. } \\
\text { Key reference: Bockarie et } \text { al }^{52}\end{array}$ & Policy option accepted \\
\hline (4) Public health education on LF & $\begin{array}{l}\text { No available evidence as a stand-alone strategy for LF control. Alternative: Integrated } \\
\text { into the community directed mass chemotherapy. Key reference: Nandha and } \\
\text { Krishnamoorthy }{ }^{53}\end{array}$ & $\begin{array}{l}\text { Policy option rejected. } \\
\text { Alternative accepted as } \\
\text { policy recommendation }\end{array}$ \\
\hline $\begin{array}{l}\text { (5) Consider LLN distribution doc/policy } \\
\text { to highlight LF }\end{array}$ & $\begin{array}{l}\text { There is evidence indicating that this should be integrated into the community } \\
\text { directed mass chemotherapy. Not as a stand-alone policy. }\end{array}$ & Policy option rejected \\
\hline $\begin{array}{l}\text { (6) Community directed distribution } \\
\text { of LLN and Mectizan (Mass }\end{array}$ & $\begin{array}{l}\text { There is sufficient evidence to show it is an effective strategy for LF control policy. } \\
\text { Key reference: Blackburn et } \mathrm{al}^{54}\end{array}$ & Policy option accepted \\
\hline
\end{tabular}

chemotherapy)/health education

\section{(7) Policy harmonization/adapting} national policies on $\mathrm{PHC}$

(8) Integrated control policy (STH, Oncho, Schisto, LF)

(9) Establishment of policy monitoring/ evaluation (feedback mechanism)/with training and capacity building

(10) Sustainability issues should be taken into consideration
No available evidence as a stand-alone strategy for LF control policy. Beyond the scope of LF policy alone. This is a health sector general problem.
Policy option rejected There is sufficient evidence to show it is an effective strategy for LF control policy. Key reference: Hopkins et al ${ }^{55}$

There is sufficient evidence to show it is an effective strategy for LF control policy. Key reference: Molyneux ${ }^{56}$

No available evidence as a stand-alone strategy for LF control policy. Beyond the scope of LF policy alone. This is a health sector general problem. Rather, Integrate sustainability into the policy implementation strategies.
Policy option accepted

Policy option accepted

Policy option rejected
(11) Success stories of previous policies and lessons learnt be adopted in LF policy formulation
No available evidence as a stand-alone strategy for LF control policy. Beyond the scope of LF policy alone. This is a health sector general problem.

Abbreviations: LF, lymphatic filariasis; LLN, long lasting insecticide treated bed-net; PHC, primary health care; STH, soil transmitted helminth infection; Oncho, onchocerciasis; Schisto, schistosomiasis.

and the goals to be achieved by specific policies. He further noted that social inequalities, changing values, and emergent challenges to traditional beliefs, add complexities that require a thorough analysis to compile policies that are fair and equitable. ${ }^{62}$

It was of interest to note that the participants were able to perform evidence synthesis for the policy briefs to identify and select policy options that were supported by relevant research evidence (Tables 5, 6 and 7). Five policy options were selected out of 13 for malaria, 3 out of 10 for schistosomiasis and 5 out of 11 for LF. The policy-makers through this process gained understanding on how to subject a policy recommendation to evidence synthesis to assess its relevance to policy. They also appreciated the enormous value of research evidence and the importance of demanding for it in policy-making. Through this approach we promoted the "pull effort" among the policy-makers. According to the $\mathrm{WHO},{ }^{63}$ pull efforts are utilized in situations where knowledge users value the use of research and recognize the need to address an information gap. Sheldon ${ }^{64}$ added that as the knowledge base is being put together in a more coordinated, explicit and credible way, so the demands for policy-makers and practitioners to use this information in their decision-making grows.

It is important to note that workshop and the mentoring in this study simultaneously improved the exchange and linkage of the participants and the researchers/mentors. Lavis and colleagues, ${ }^{23}$ noted in their report that such exchange and linkage enhance evidence-to-policy link and knowledge translation (referred to as the integrated model). It is interesting to note that the policy-makers continue to receive support from the mentors (researchers) even after the end of the training workshop main activities. It is well-established that a major factor that can bridge the gaps in evidence to policy process is sufficient contact between researchers and policy-makers. ${ }^{65}$ In our previous study, participants in the focus group discussion conducted in this study were in consensus that collaboration between researchers and policymakers was needful so as to align researchers more specifically to operational problems inherent in the health systems from the policy-making perspective. ${ }^{66}$

A very notable initiative in this study was the inclusion in the content of the training of policy-makers of topics on ethics in policy-making, and policy implementation which seldom are addressed in EIP initiatives. ${ }^{67}$ Hyder and colleagues ${ }^{68}$ noted in their report that ethics is gradually being integrated into public-health policy decisions in many developing health systems, even though it is often implicit and undervalued. They added that while there have been extensive explorations 
of public-health policy in LMICs (such as by WHO), they have tended to focus on the attributes of specific health policies and systems rather than the role of ethics in the policy process. ${ }^{68}$ Ethical issues highlighted in this study such as balancing ethical concerns with economic realities; impact of various policies on the vulnerable population; and the principles of justice, equity and autonomy in policy-making are vital factors that are often not given due consideration in low-income settings. Because studies on ethics in health policy-making and implementation are scarce more studies are not only needed in this field but also policy-makers should be trained to identify local values and public-health policies through valid research, and the provision of complementary support and guidance to promote social justice, accountability and preventive practices in an inherently unstable environment. ${ }^{68}$

\section{Conclusion}

It is pertinent to state that the result of this study clearly suggests that an evidence-to-policy capacity enhancement workshop combined with a mentorship programme can improve policy-makers' capacity for EIP. There are two major limitations to this study. First, the short period of time for the capacity enhancement workshop (2 days) and that of the mentorship programme ( 2 months) may not have been very sufficient to build real capacity in the policy-makers to produce evidence tools such as policy briefs. One of the participants commented thus: "The workshop has been very interesting but there is no time to digest the papers well. We need more of this programme." Another policy-maker added that: "This health policy programme should be organised at least every three months for us to be well-equipped in the rudiments of policy-making." According SURE Collaboration report, ${ }^{35}$ preparing and using policy briefs requires a range of knowledge and skills, and typically these competencies need to be developed over a period of years. The second limitation has to do with the self-assessment technique used to evaluate study outcome. Deans and Ademokun, ${ }^{1}$ highlighting the weakness of this technique noted that being able to critically recognize and understand one's own gap in skills and knowledge is a difficult process which takes guided thought. Despite these limitations, there is little doubt that workshops and mentorship programmes can be used for policy-makers' capacity enhancement. We recommend that future studies could increase the duration of this type of capacity enhancement initiative and a more robust evaluation mechanism can be employed such as the diagnostic technique proposed by Haahr and colleagues ${ }^{69}$ Furthermore we propose that additional work is necessary to assess the impact of the capacity of policy-makers to implement their crafted policies and assess the impact of the workshop to consolidate a sustainable knowledge translation platform that combines policy-makers and researchers/mentors by establishing constant exchanges and linkages among them.

\section{Acknowledgments}

This investigation received financial support from the UNCICEF/UNDP/World Bank/WHO Special Programme for Research and Training in Tropical Diseases (WHO/ TDR), (Reference 2014/397653-0). Authors are grateful to the Commissioner for Health Ebonyi State Dr. Sunday Nwangele; the Permanent Secretary Ministry of Health Ebonyi State Mr. Hyacinth Ote and Permanent Secretary Office of the Head of Service Ebonyi State Elder Kingsley Obini for all their support. Authors wish to thank all the policy-makers of Ebonyi State Nigeria who participated in this study for their commitment.

\begin{abstract}
Ethical issues
Approval for this study was obtained from the Directorate of Research, Innovation and Commercialization (DRIC), Ebonyi State University, Abakaliki, Nigeria. The approval was based on the agreement that participation in the research was voluntary following informed consent; that participants' anonymity would be maintained; and that every finding would be treated with utmost confidentiality and for the purpose of this research. These were adhered to in this study.
\end{abstract}

Competing interests

Authors declare that they have no competing interests.

\section{Authors' contributions}

CJU and AEE conceived the idea. All authors contributed to the development of the idea and execution of the study. All authors participated in all the training activities, contributed to the drafting and revision of the manuscript.

\section{Authors' affiliations}

1Department of Medical Microbiology/Parasitology, Faculty of Clinical Medicine, Ebonyi State University, Abakaliki, Nigeria . ${ }^{2}$ Health Policy \& systems Research Project (Knowledge Translation Platform), Ebonyi State University, Abakaliki, Nigeria. ${ }^{3}$ Department of Banking \& Finance, Ebonyi State University, Abakaliki, Nigeria. ${ }^{4}$ National Obstetrics Fistula Centre, Abakaliki, Nigeria. ${ }^{5}$ Department of Paediatrics, Ebonyi State University, Abakaliki, Nigeria. ${ }^{6}$ Department of Applied Microbiology, Ebonyi State University, Abakaliki, Nigeria. ${ }^{7}$ Department of Sociology/Anthropology, Ebonyi State University, Abakaliki, Nigeria. ${ }^{8} \mathrm{Catholic}$ Relief Services (Nigeria Program), Abakaliki, Nigeria.

\section{References}

1. Deans F, Ademokun A. Investigating capacity to use evidence. International Network for the Availability of Scientific Publications (INASP). http://www.inasp.info/uploads/filer_public/2013/07/04/ investigating_capacity_to_use_evidence.pdf. Accessed February 14, 2015.

2. Oxman AD, Lavis JN, Lewin S, Fretheim A. SUPPORT Tools for evidence-informed health Policymaking (STP) 1: What is evidence-informed policymaking? Health Res Policy Syst. 2009;7 Suppl 1:S1. doi:10.1186/1478-4505-7-s1-s1

3. Bowen S, Zwi AB. Pathways to "evidence-informed" policy and practice: a framework for action. PLoS Med. 2005;2(7):e166. doi:10.1371/journal.pmed.0020166

4. Campbell DM, Redman S, Jorm L, Cooke M, Zwi AB, Rychetnik L. Increasing the use of evidence in health policy: practice and views of policy makers and researchers. Aust New Zealand Health Policy. 2009;6:21. doi:10.1371/journal. pmed.0020166

5. Dobrow MJ, Goel V, Upshur RE. Evidence-based health policy: context and utilisation. Soc Sci Med. 2004;58:207-217. doi:10.1016/s0277-9536(03)00166-7

6. Hanney SR, Gonzalez-Block MA, Buxton MJ, Kogan M. The utilization of health research in policy-making: concepts, examples and methods of assessment. Health Res Policy Syst. 2003;1:2-29.

7. Innvær S, Vist G, Trommald M, Oxman A. Health policymakers perceptions of their use of evidence: a systematic review. J Health Serv Res Policy. 2002;7:239-244. doi:10.1258/135581902320432778

8. Oxman AD, Lavis JN, Fretheim A. The use of evidence in WHO 
recommendations. Lancet 2007;369:1883-1889. doi:10.1016/ s0140-6736(07)60675-8

9. Lavis JN, Davies HT, Oxman A, Denis JL, Golden-Biddle K, Ferlie E. Towards systematic reviews that inform healthcare management and policymaking. J Health Serv Res Policy. 2005; 10:35-48.

10. Lavis JN, Ross SE, Hurley JE, et al. Examining the role of health services research in public policymaking. Milbank $Q$. 2002;80:125-154.

11. Moat KA, Lavis JN, Clancy SJ, El-Jardali F, Pantoja T. Evidence briefs and deliberative dialogues: perceptions and intentions to act on what was learnt. Bull World Health Organ. 2014;92(1):2028. doi:10.2471/blt.12.116806

12. El-Jardali F, Lavis J, Moat K, Pantoja T, Ataya N. Capturing lessons learned from evidence-to-policy initiatives through structured reflection. Health Res Policy Syst. 2014;12:2. doi:10.1186/1478-4505-12-2

13. Lavis JN, Panisset U. EVIPNet Africa's first series of policy briefs to support evidence-informed policymaking. Int J Tech Assess Health Care. 2010;26(02):229-232.

14. World Health Organization (WHO). World Health Organization 2012: GlobalReportforResearchon Infectious DiseasesofPoverty. http://whqlibdoc.who.int/publications/2012/9789241564489 eng.pdf. Accessed February 14, 2015.

15. World Health Organization (WHO). World Malaria Report 2014. Geneva: Switzerland; 2014:242.

16. Okorie PN, Ademowo GO, Saka Y, et al. Lymphatic filariasis in Nigeria; Micro-stratification Overlap Mapping (MOM) as a prerequisite for cost-effective resource utilization in control and surveillance. PLoS Negl Trop Dis. 2013;7(9):e2416. doi:10.1371/ journal.pntd.0002416

17. World Health Organization (WHO). Global programme to eliminate lymphatic filariasis: progress report. Wkly Epidemiol Rec. 2011;87:346-356.

18. Hotez PJ, Asojo OA, Adesina AM. Nigeria: "Ground Zero" for the High Prevalence Neglected Tropical Diseases. PLoS Negl Trop Dis. 2012;6:e1600. doi:10.1371/journal.pntd.0001600

19. Adenowo AF, Oyinloye BE, Ogunyinka BI, Kappo AP. Impact of human schistosomiasis in sub-Saharan Africa. Braz J Infect Dis. 2015;19(2):196-205. doi:10.1016/j.bjid.2014.11.004

20. Adam T, Moat KA, Ghaffar A, Lavis JN. Towards a better understanding of the nomenclature used in informationpackaging efforts to support evidence-informed policymaking in low- and middle-income countries. Implement Sci. 2014;9:67. doi:10.1186/1748-5908-9-67

21. Lavis JN. How can we support the use of systematic reviews in policymaking? PloS Med. 2009;6(11):e1000141. doi:10.1371/ journal. pmed.1000141

22. Rosenbaum SE, Glenton C, Wiysonge CS, et al. Evidence summaries tailored to health policy-makers in low- and middleincome countries. Bull World Health Organ. 2011;89(1):54-61.

23. Lavis JN, Lomas J, Harnid M, Sewankambo NK. Assessing country-level efforts to link research to action. Bull World Health Organ. 2006;84:620-628.

24. Feldman PH, Nadash P, Gursen M. Improving communication between researchers and policy makers in long-term care or "researchers are from Mars; policy makers are from Venus". Policy Brief (Cent Home Care Policy Res). 2001;(5):1-6. doi:10.1093/geront/41.3.312

25. Coburn $A$. The role of health services research in developing state health policy. Health Affairs. 1998;17(1):139-151. doi:10.1377/hlthaff.17.1.139

26. Lomas J. Using "linkage and exchange" to move research into policy at a Canadian foundation. Health Affairs 2000;19:236-240.

27. Roos NL, Shapiro E. From research to policy: What have we learned? Med Care. 1999;37:JS291-JS305.
28. Lavis JN, Permanand G, Oxman AD, Lewin S, Fretheim A. SUPPORT Tools for evidence-informed health Policymaking (STP) 13: Preparing and using policy briefs to support evidenceinformed policymaking. Health Res Policy Syst. 2009;16;7(suppl 1):S13. doi:10.1186/1478-4505-7-S1-S13

29. Brownson RC, Dodson EA,Stamatakis KA, et al. Communicating evidence-based information on cancer prevention to statelevel policy makers. J Natl Cancer Inst. 2011; 103(4):306-316. doi:10.1093/jnci/djq529

30. International Development Research Centre, Swiss Agency for Development and Cooperation. Chapter 8: The Two-Pager: Writing a policy brief. In: The RM Knowledge Translation Toolkit: A Resource for Researchers. Ottawa, Canada: IDRC and SADC; 2008.

31. Stamatakis K, McBride T, Brownson R. Communicating prevention messages to policy makers: the role of stories in promoting physical activity. J Phys Act Health. 2010;7(suppl 1):S99-S107.

32. Green A, Bennett S, eds. Sound choices: enhancing capacity for evidence-informed health policy. Geneva: World Health Organization; 2007.

33. DeMarco R, Tufts KA. The mechanics of writing a policy brief. Nurs Outlook. 2014;62(3):219-224. doi:10.1016/j. outlook.2014.04.002

34. Jones JA. Political science? strengthening science-policy dialogue in developing countries. London: ODI; 2008.

35. The SURE Collaboration. SURE Guides for Preparing and Using Evidence-Based Policy Briefs: 1. Getting started. Version 2.1. http://global.evipnet.org/sure/. Published 2011. Updated November 2011.

36. Purdon S, Lessof C, Woodfield K, Bryson C. Research methods for policy evaluation. National Centre for Social Research. http:// www.academia.edu/1967742/Research_methods_for_policy_ evaluation. Published 2001. Accessed February 14, 2015.

37. Bammer G, Strazdins L, McDonald D, et al. Expanding the deliberations about the research-policy gap: useful lessons from the literature. In: Bammer G, Michaux A, Sanson A, eds. Bridging the 'know-do' gap: Knowledge brokering to improve child wellbeing. Canberra, Australia: ANU E-Press; 2010:135-155.

38. Canadian Coalition for Global Health Research (CCGHR). Module Three: Why Mentorship? http://www.ccghr.ca/wp-content/ uploads/2013/05/Mentoring_Module3_Why-Mentorship_e.pdf. Published 2001. Accessed February 14, 2015.

39. Johnson NA, Lavis JN. Procedures Manual for the 'Evaluating Knowledge Translation Platforms in Low- and Middle-Income Countries' Study. Hamilton, Canada: McMaster University Program in Policy Decision-Making; 2009.

40. Tusting LS, Thwing J, Sinclair D, et al. Mosquito larval source management for controlling malaria. Cochrane Database Syst Rev. 2013;8:CD008923. doi: 10.1002/14651858.CD008923. pub2

41. Gamble CL, Ekwaru JP, ter Kuile FO. Insecticide-treated nets for preventing malaria in pregnancy. Cochrane Database Syst Rev 2006;2:CD003755. doi:10.1002/14651858.CD003755.pub2

42. Poirot E, Skarbinski J, Sinclair D, Kachur SP, Slutsker L, Hwang J. Mass drug administration for malaria. Cochrane Database Syst Rev 2013;12:CD008846. doi:10.1002/14651858.CD008846. pub2

43. Odaga J, Sinclair D, Lokong JA, Donegan S, Hopkins H, Garner $P$. Rapid diagnostic tests versus clinical diagnosis for managing people with fever in malaria endemic settings. Cochrane Database Syst Rev 2014;4:CD008998. doi:10.1002/14651858. CD008998.pub2

44. Abuya TO, Mutemi W, Karisa B, Ochola SA, Fegan G, Marsh V. Use of over-the-counter malaria medicines in children and adults in three districts in Kenya: implications for private medicine 
retailer interventions. Malar J 2007;6:57. doi:10.1186/14752875-6-57

45. Ogbonna A, Uneke CJ. Artemisinin-based combination therapy for uncomplicated malaria in sub-Saharan Africa: the efficacy, safety, resistance and policy implementation since Abuja 2000. Trans R Soc Trop Med Hyg. 2008;102(7):621-627.

46. Amoa Onguéné $P$, Ntie-Kang F, Lifongo LL, Ndom JC, Sippl W, Mbaze LM. The potential of anti-malarial compounds derived from African medicinal plants. Part I: A pharmacological evaluation of alkaloids and terpenoids. Malar $J$ 2013;12:449. doi:10.1186/1475-2875-12-449

47. Pluess B, Tanser FC, Lengeler C, Sharp BL. Indoor residual spraying for preventing malaria. Cochrane Database Syst Rev 2010;4:CD006657. doi:10.1002/14651858.CD006657.pub2

48. Yuan Y, Xu XJ, Dong HF, Jiang MS, Zhu HG. Transmission control of schistosomiasis japonica: implementation and evaluation of different snail control interventions Acta Trop. 2005;96(2-3):191-197.

49. Hu GH, Hu J, Song KY, et al. The role of health education and health promotion in the control of schistosomiasis: experiences from a 12-year intervention study in the Poyang Lake area. Acta Trop. 2005;96(2-3):232-241.

50. Su J, Lu DB, Zhou X, Wang SR, Zhuge HX. Control efficacy of annual community-wide treatment against Schistosoma japonicum in China: a meta-analysis. PLoS One. 2013;8(11):e78509. doi:10.1371/journal.pone.0078509

51. Weil GJ, Ramzy RM. Diagnostic tools for filariasis elimination programs. Trends Parasitol. 2007;23(2):78-82.

52. Bockarie MJ, Pedersen EM, White GB, Michael E. Role of Vector Control in the Global Program to Eliminate Lymphatic Filariasis. Annu Rev Entomol. 2009;54:469-87. doi:10.1146/annurev. ento.54.110807.090626

53. Nandha B, Krishnamoorthy K. School-based health education campaign--a potential tool for social mobilization to promote the use of DEC-fortified salt towards elimination of lymphatic filariasis. Health Educ Res. 2007;22(4):539-546.

54. Blackburn BG, Eigege A, Gotau $H$, et al. Successful integration of insecticide-treated bed net distribution with mass drug administration in Central Nigeria. Am J Trop Med Hyg.2006;75(4):650-655.

55. Hopkins DR, Eigege A, Miri ES, et al. Lymphatic filariasis elimination and schistosomiasis control in combination with onchocerciasis control in Nigeria. Am J Trop Med Hyg. 2002;67(3):266-272.

56. Molyneux DH. Filaria control and elimination: diagnostic, monitoring and surveillance needs. Trans $R$ Soc Trop Med Hyg. 2009;103(4):338-341. doi:10.1016/j.trstmh.2008.12.016
57. Healthcare for all (HIFA). CHILD2015 Summary: Are workshops effective? http://www.hifa2015.org/wp-content/uploads/2008/09/ training_workshops_are_they_effective.pdf. Published 2008. Accessed February 14, 2015.

58. Poulos RG, Zwi AB, Lord SR. Towards enhancing national capacity for evidence informed policy and practice in falls management: a role for a "Translation Task Group"? Aust New Zealand Health Policy. 2007;31:4:6. doi:10.1186/1743-8462-4-6

59. Bennett S, Paina L, Kim C, et al. What must be done to enhance capacity for Health Systems Research? Background paper for the global symposium on health systems research 16-19 November 2010, Montreux, Switzerland.

60. Prewitt K. Winning the policy wars. London, UK: Global Public Policy Network, London school of economics and political sciences; 2006.

61. Overseas Development Institute (ODI). Bridging research and policy in international development: an analytical and practical framework. Research and Policy in Development Programme Briefing Paper No. 1. London: Overseas Development Institute; 2004.

62. Aarons DE. Issues in bioethics: ethics in health policy and guidelines in healthcare. West Indian Med J. 2006;55(2):113119.

63. World Health Organization (WHO). Knowledge Translation on Ageing and Health: A Framework for Policy Development. Geneva, Switzerland: WHO; 2012

64. Sheldon TA. Making evidence synthesis more useful for management and policy-making. J Health Serv Res Policy. 2005;10(suppl 1):1-5.

65. Alliance for Health Policy and Systems Research (AHPSR). Sound choices: enhancing capacity for evidence-informed health policy. Geneva: World Health Organization; 2007.

66. Uneke CJ, Ezeoha AE, Ndukwe CD, Oyibo PG, Onwe F. Promotion of evidence-informed health policymaking in Nigeria: bridging the gap between researchers and policymakers. Global Public Health 2012;7(7):750-765.

67. Anand K, Baridalyne N, Moorthy D, Kapoor SK, Sankar $\mathrm{R}$, Pandav CS. Ethical issues in public health policy. Natl Med J India. 2002;15(2):97-100.

68. Hyder AA, Merritt M, Ali J, Tran NT, Subramaniam K, Akhtar $\mathrm{T}$. Integrating ethics, health policy and health systems in lowand middle-income countries: case studies from Malaysia and Pakistan. Bull World Health Organ. 2008;86(8):606-611.

69. Haahr JH, Shapiro H, Sorensen S, et al. Defining a Strategy for the Direct Assessment of Skills. Brussels, Belgium: European Commission, Directorate General for Education and Culture; 2004:141. 